\title{
Effect of Non-Delineated Normal Volumes in IMRT Treatment for Left Breast Cancer: A Treatment Planning Study
}

\author{
Tamer Dawod1, Sabbah I. Hammoury ${ }^{2 *}$, Mostafa Elnaggar3 ${ }^{3}$ Mustafa Kamal4 \\ ${ }^{1}$ Clinical Oncology and Nuclear Medicine Department, Faculty of Medicine, Mansoura University, Mansoura, \\ Egypt \\ ${ }^{2}$ Medical Physics Department, Alexandria Ayadi Almostakbl Oncology Center (AAAOC), Alexandria, Egypt \\ ${ }^{3}$ Department of Cancer Management and Research Medical Research Institute, Alexandria University, \\ Alexandria, Egypt \\ ${ }^{4}$ Metal Physics Lab, Physics Department, Faculty of Science, Mansoura University, Mansoura, Egypt \\ Email: tamerdawod@gmail.com, sabbah ibrahiem@yahoo.com, elnaggarmost@yahoo.co.uk, \\ kamalmustafa144@gmail.com
}

Received 23 December 2014; accepted 10 January 2015; published 16 January 2015

Copyright (C) 2015 by authors and Scientific Research Publishing Inc.

This work is licensed under the Creative Commons Attribution International License (CC BY). http://creativecommons.org/licenses/by/4.0/

\section{(c) (i) Open Access}

\begin{abstract}
Introduction: Intensity Modulated Radiation Therapy (IMRT) planning dose calculation process depends on IMRT dose constraints. So, if there was any structure along the treatment beam path not delineated, it would not be taken into account during that calculation process. During IMRT routine practical work, it is noticed that there are some non-delineated normal tissue volumes that received un-aimed dose. Aim: The purpose of this study was to study the effect of unusually delineated normal volumes in IMRT treatment for left sided breast cancer. Method: Ten left sided breast cancer patients were planned with IMRT inverse planning system. The unusually delineated normal volumes were delineated and taken into account in IMRT dose constraints as an Organ at Risk. Doses received by that volume were compared in the two methods quantitatively from Dose Volume Histograms (DVHs) and qualitatively from (axial cuts). Results: The results showed that doses received by the unusually delineated volume when they were delineated and taken into account in IMRT dose constraints were significantly higher than when they were not. Conclusions: The results showed that for IMRT planning technique used for treating left-sided breast cancer, all of the normal tissues/structures that are closed to the treatment targets must be delineated and taken into account in the IMRT planning dose constraints.
\end{abstract}

\section{Keywords}

Radiotherapy, IMRT, Linear Accelerator, Treatment Planning System TPS, NTIAV

\footnotetext{
${ }^{*}$ Corresponding author.
}

How to cite this paper: Dawod, T., Hammoury, S.I., Elnaggar, M. and Kamal, M. (2015) Effect of Non-Delineated Normal Volumes in IMRT Treatment for Left Breast Cancer: A Treatment Planning Study. International Journal of Medical Physics, Clinical Engineering and Radiation Oncology, 4, 13-24. http://dx.doi.org/10.4236/ijmpcero.2015.41003 


\section{Introduction}

Conformal radiation therapy (CRT) techniques aim to achieve a high-dose region which conforms as closely as possible to the target volume, thereby enabling both the sparing of normal tissues and radiation dose-escalation [1]-[3].

IMRT involves adjusting the beam-intensity to permit even more conformal dose distributions. In IMRT, the intensity of radiation exposure in one portion of the field is modified depending on whether tumor or normal tissue is present in the beam pathway. To do this, IMRT divides the beam into multiple beamlets. When the beamlet hits normal tissues, the intensity is lowered, and when the beamlet hits tumor, the intensity is higher. The changing of beam intensity is computer controlled. So, delineation of both clinical target volumes and organs at risk is very important when in IMRT in order to achieve its required results [4]-[6].

The IMRT planning dose calculation process depends on IMRT dose constraints. So, if there was any structure along the treatment beam path not delineated, it would not be taken into account during that calculation process.

In general IMRT practical work for several types of tumor cancer (i.e. prostate cancer, head and neck cancer, breast cancer), it is noticed that there are some non-delineated normal tissue volumes that received un-aimed dose [7] [8]. For breast cancer (as the aim of the work), these volumes may include (in some cases), a part of the stomach and/or a part of the liver and sometimes other normal tissues that come with the lower part of the left breast and with the upper part of the left lung. All or some of these volumes are not usually delineated or not taken into account in the IMRT planning dose constraints. These volumes can receive unwanted doses and can be covered by isodose lines of high values (i.e. the $70 \%, 80 \%, 85 \%, 90 \%$ and $95 \%$ isodose lines) because that the IMRT inverse planning doesn't take it into consideration during its dose calculation process.

\section{Materials and Methods}

\subsection{Acquisition and Simulation}

Ten left-sided breast cancer patients underwent a Computed Tomography (CT) scan with $2 \mathrm{~mm}$ slice thickness. All sets of CT cuts were transferred to Focal system. Tumor volumes such as gross target volume (GTV), clinical target volume (CTV), and planning target volume (PTV) [9] as well as Organs at Risk (OARs) had been delineated by the physician on each axial slice, then CT slices were transferred to the treatment planning system (TPS).

\subsection{Treatment Planning System}

Three-dimensional treatment inverse planning system (CMS) XiO software (release 4.64) was used to carry out dose calculation for all patients under study by Super position algorithm.

$\mathrm{XiO}$ employs a conjugate gradient algorithm to search for the minimum value of the cost function, which was a member of the gradient descent family of optimization methods, where variables were changed systematically, as opposed to stochastic methods where variables were changed randomly. The beam parameters were adjusted by changing the intensity distribution, which was physically achieved by creating a series of multileaf collimator (MLC) field segments and assigning a monitor unit (MU) weighting to each. The series of field segments that make up a beam were called a leaf sequence. To control this conversion process the acceptable percentage difference between the desired and the actual dose distribution can be specified. Currently a $2 \%$ match was specified, and this typically leads to the generation of 10 to 20 segments per field. The minimum segment Monitor Units (MUs) and field size can also be specified.

\subsection{Beams Arrangement}

The beam arrangement was determined by the size and location of the tumor. Major five fields with equal values of dose were used to plan each patient. IMRT plans were generated using commercial inverse planning software [10] [11]. The beams are spread around the target with equispace and to avoid the opposing fields an odd numbers of the treatment fields were used. IMRT dose constraints for both target and OARs were entered to Xio TPS [12]-[14]. Also some conditions were given to the inverse TPS which were the minimum, goal and maximum radiation doses for the target volume, the power and weight of each structure (Figure 1). Several trials 


\begin{tabular}{|c|c|c|c|c|c|c|c|c|}
\hline \multicolumn{9}{|c|}{ IMRT Prescription } \\
\hline Structure & Type & Rank & objective & Dose (cGy) & Volume (\%) & Weight & Power & Status \\
\hline \multirow[t]{3}{*}{ Lt lung } & OAR & 2 & Maximum & 1100 & 0 & 100 & 3.0 & On \\
\hline & & & Dose Volune & 700 & 10 & 100 & 2.7 & on \\
\hline & & & Dose Volune & 600 & 20 & 100 & 2.5 & On \\
\hline Heart & OAR & 3 & Maximum & 500 & 0 & 100 & 3.0 & On \\
\hline cord & OAR & 5 & & & & & & \\
\hline Rt breast & OAR & 4 & Maximum & 400 & 0 & 100 & 2.0 & On \\
\hline \multirow[t]{3}{*}{ Lt braest } & Target & 1 & Maximum & 5100 & 0 & 1000 & 3.5 & On \\
\hline & & & Goal & 5025 & 100 & & 1.0 & On \\
\hline & & & Minimum & 5000 & 100 & 100 & 3.5 & On \\
\hline Skin & OAR & 6 & & & & & & \\
\hline
\end{tabular}

Figure 1. IMRT dose constraints for both of the treatment target and OARs for treating the left breast cancer patients under the study.

were taken place by Inverse TPS to achieve the IMRT dose constraints and a homogeneous dose distribution [11] [12].

\subsection{Evaluation of the Treatment Plans}

The treatment plans can be qualitatively and quantitatively evaluated by many tools which are already included into Xio TPS. In our study, we used two main treatment plan evaluation tools; the visual slice-by slice review of the treatment plans using isodose lines distribution as a qualitative evaluation for the treatment plans which is important to know the location of the hot and cold areas and review dose distribution to both of the clinical target (in our study is the left breast) and OARs (in our study are ipsilateral lung, heart, contralateral breast ) and the Dose Volume Histogram (DVH) was generated to evaluate the dose to the different structures in different treatment plans and it can be used as a quantitative evaluation for the treatment plans [15]-[17]. However, DVHs do not provide spatial information such as the location of the high- and low-dose regions ("hot" and "cold" spots) inside the volume of interest (VOI) [18] [19].

\subsection{Delineating the Non-Delineated Normal Tissue Volumes in the Plan}

That unusually delineated normal volume and additional portion beside it are delineated as a single structure. We called that as (The Non-Taken Into-Account Volume (NTIAV)) and considered it as an OAR so we referred to it by (OAR4) (where the number 4 refers to that that volume is the organ at risk number 4 after the three usually contoured organs at risk (ipsilateral lung, heart, and contralateral breast).

\section{Results}

\subsection{According to a Qualitative Evaluation Tool (the Axial Cuts)}

According to the next two axial cuts groups (a) and (b) (Figure 2) for ten patients respectively and as compared in the two methods of being the NTIAV was non-taken into dose constraints account and when it was taken, a large partition of it was covered with some of high value isodose lines like the $90 \%, 80 \%$, and $70 \%$ of the prescribed dose in the case of being it not taken into account as it is shown in Figure 2(a). But the same volume was significantly spared in the case of being it taken into dose constraint account as it is shown in Figure 2(b).

The axial cuts in groups (a) and (b) for patients no.4, 5 and 6, showed a very important reason for that significant difference between the two plans. It is noticed in (a) that isodose lines passed away sparing the left lung but distributed across the NTIAV. This means that the treatment plan didn't consider with that Non-Taken IntoAccount Volume and distributed the dose across it in order to achieve the other given dose constraints before. But in (b), it is noticed that the plan took that volume into its dose calculation considerations so it spared it to be not covered with high isodose values.

High values isodose lines can also cover a portion of the liver, a portion of colon in addition to that one of the 
Patient no.1:

(a)

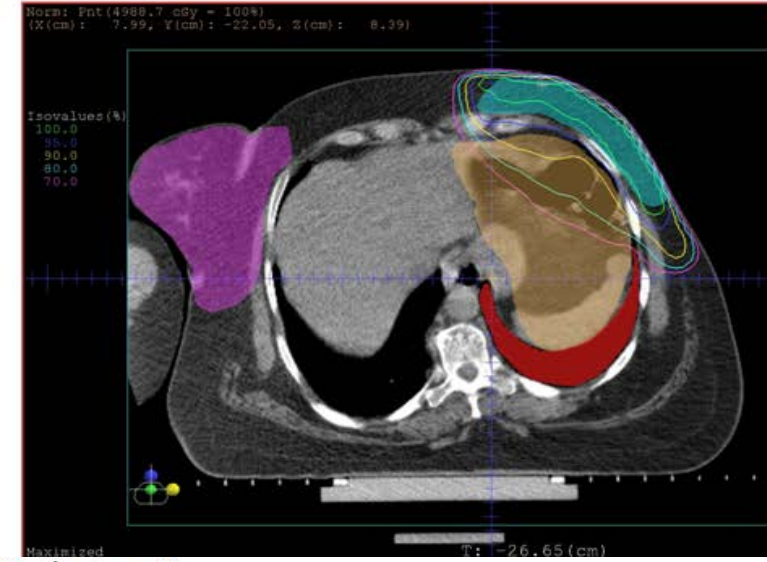

Patient no.2:

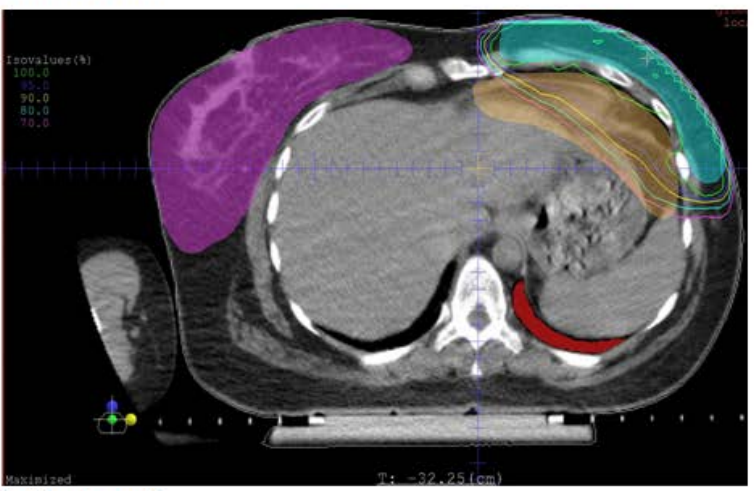

Patient no.3:

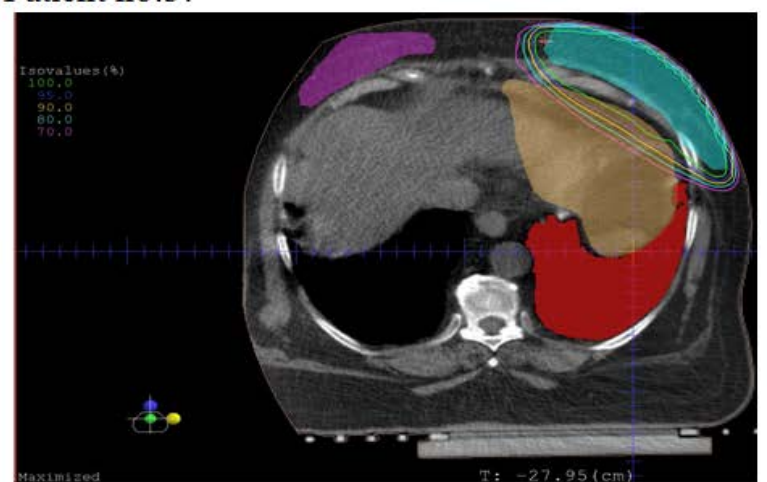

Patient no.4:

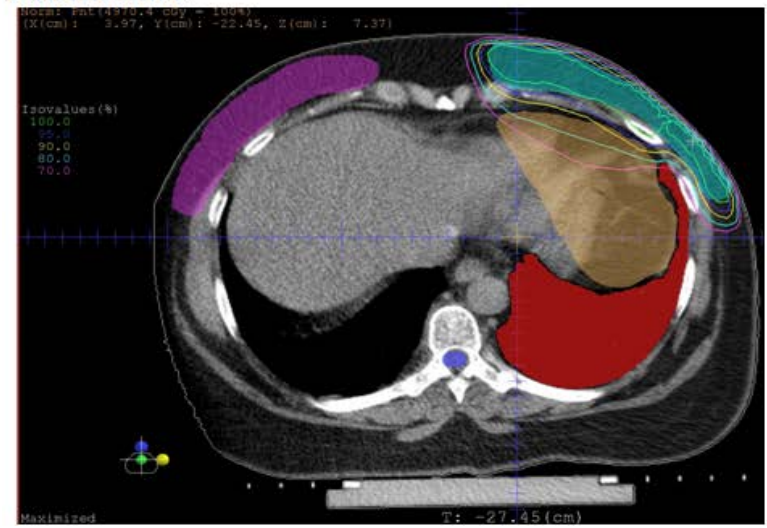

(b)
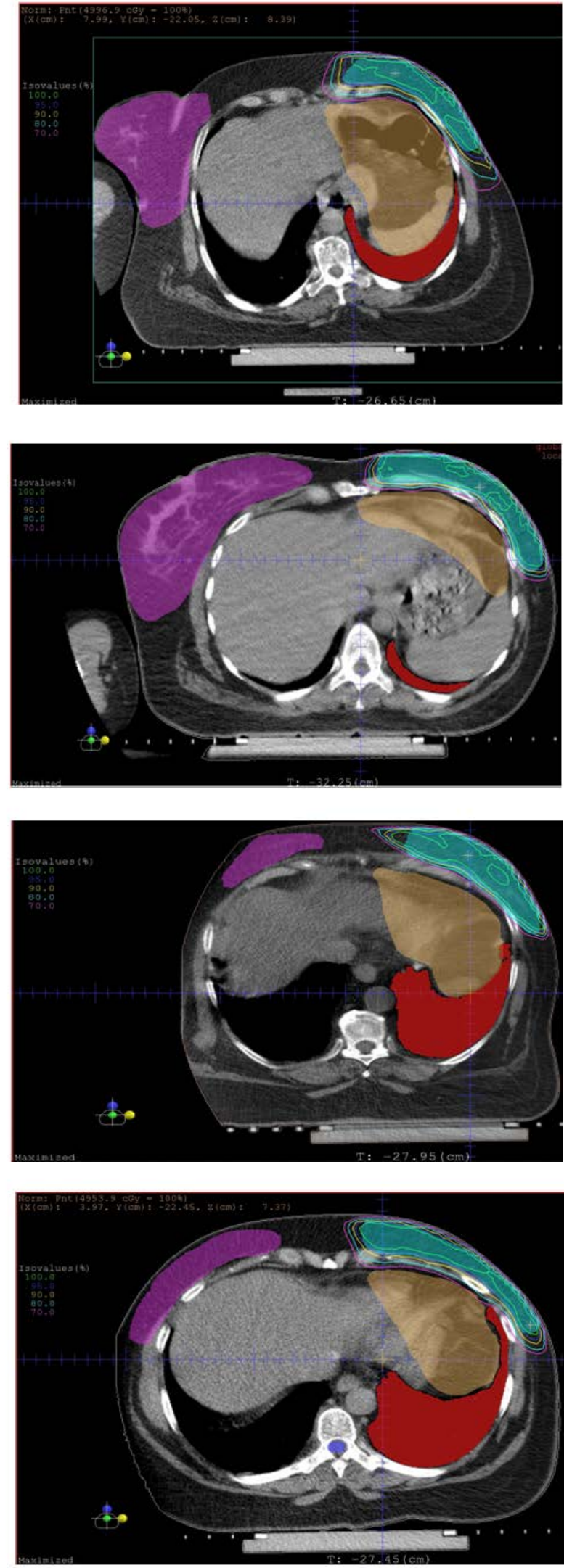


\section{Patient no.5:}
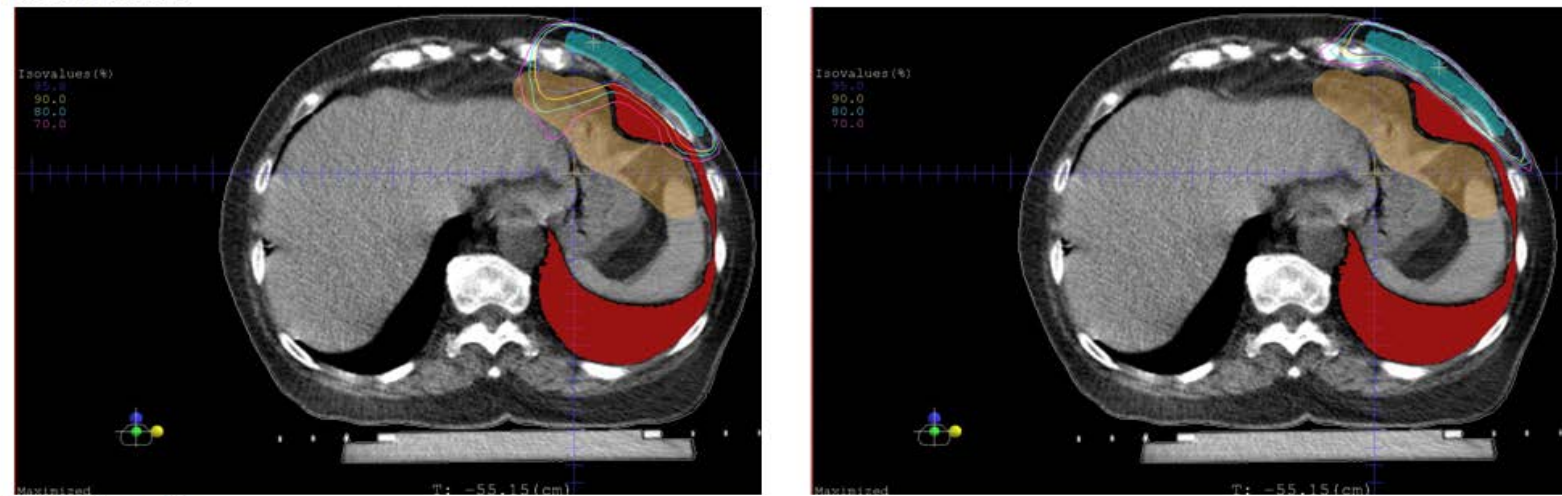

Patient no.6:
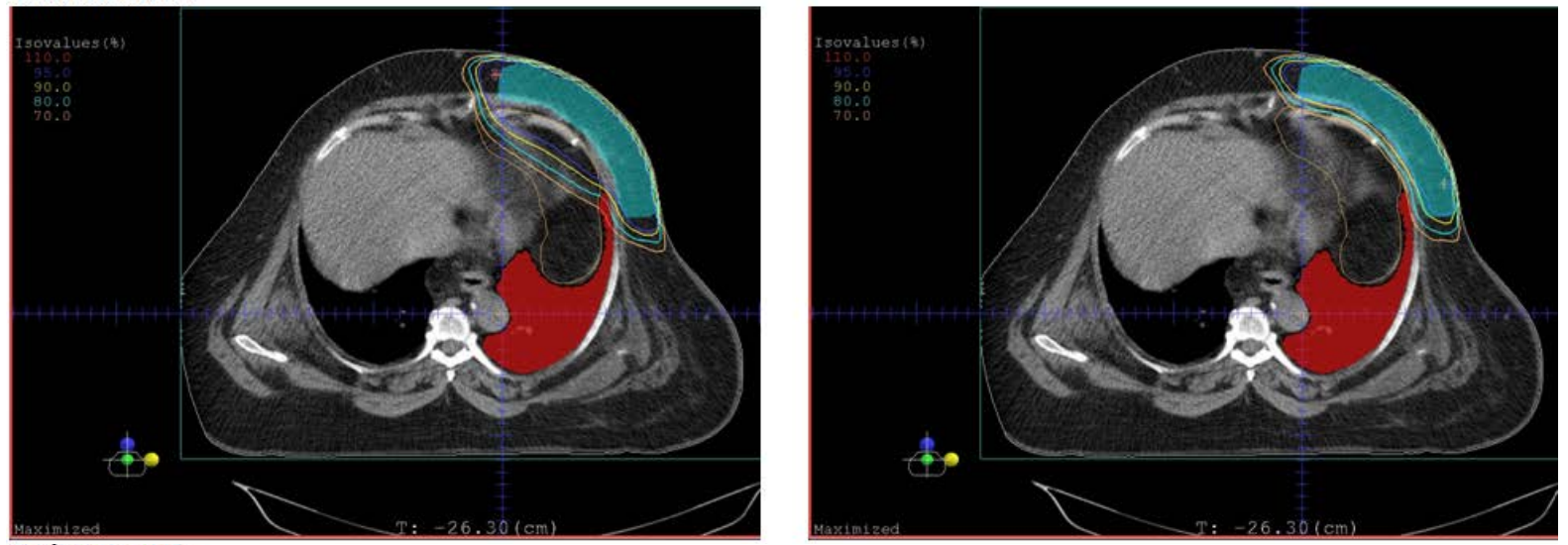

Patient no.7:
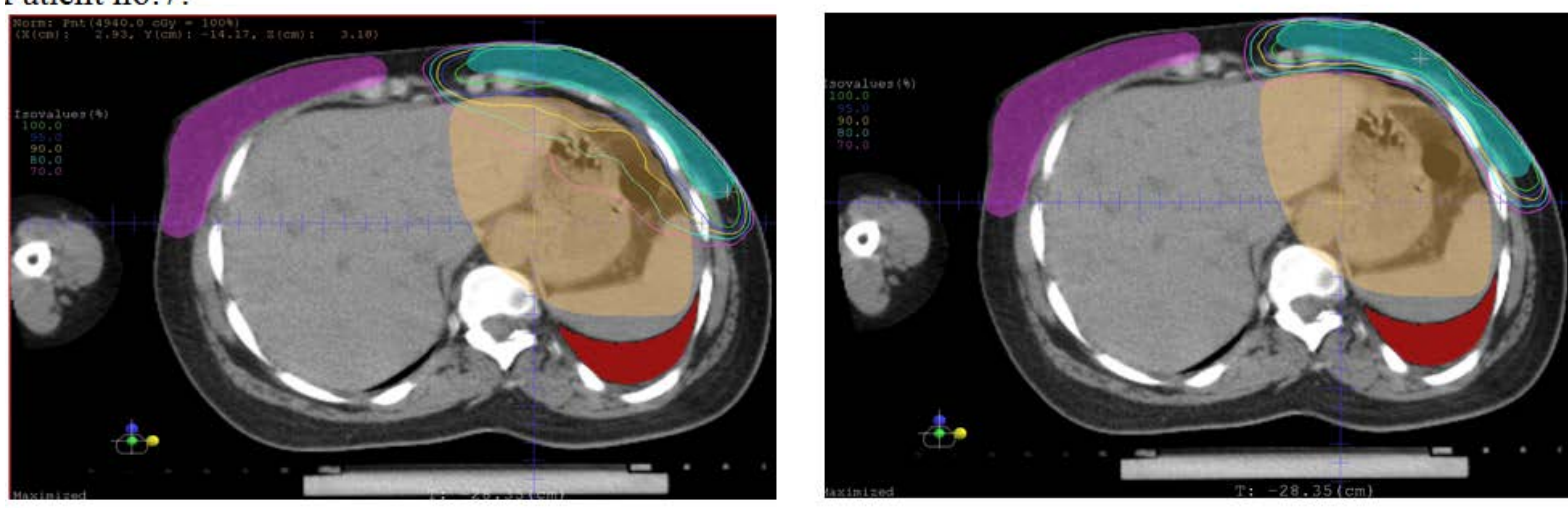

Patient no.8:
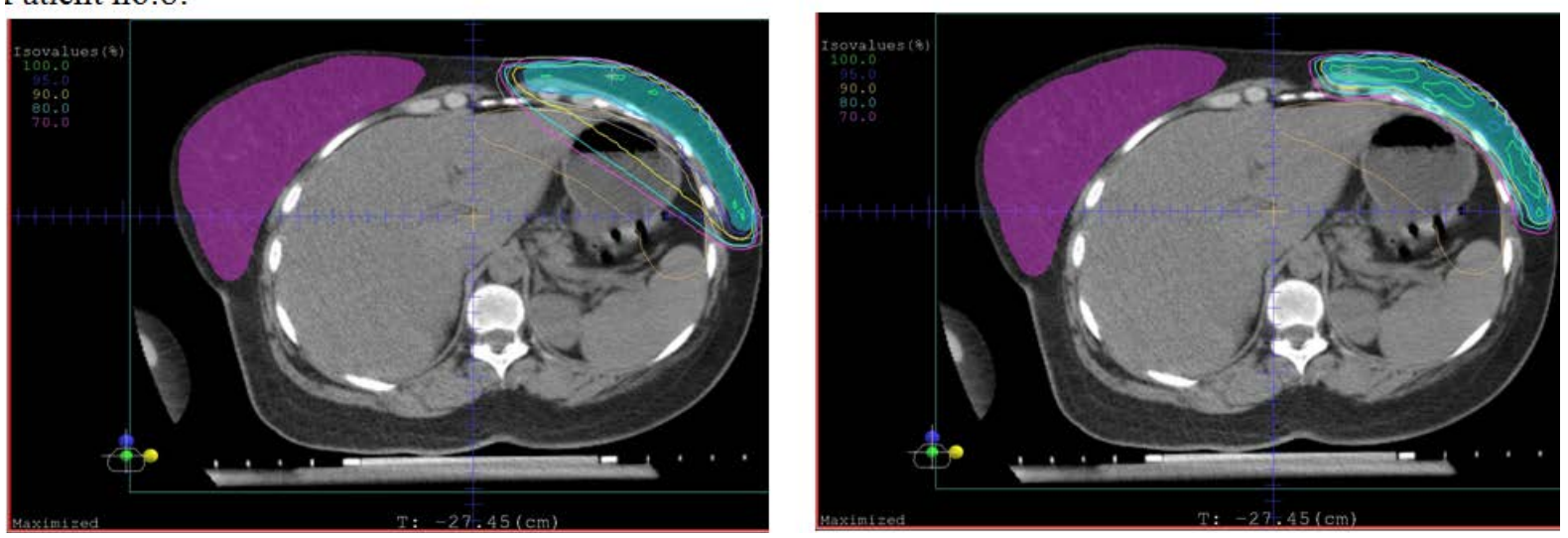

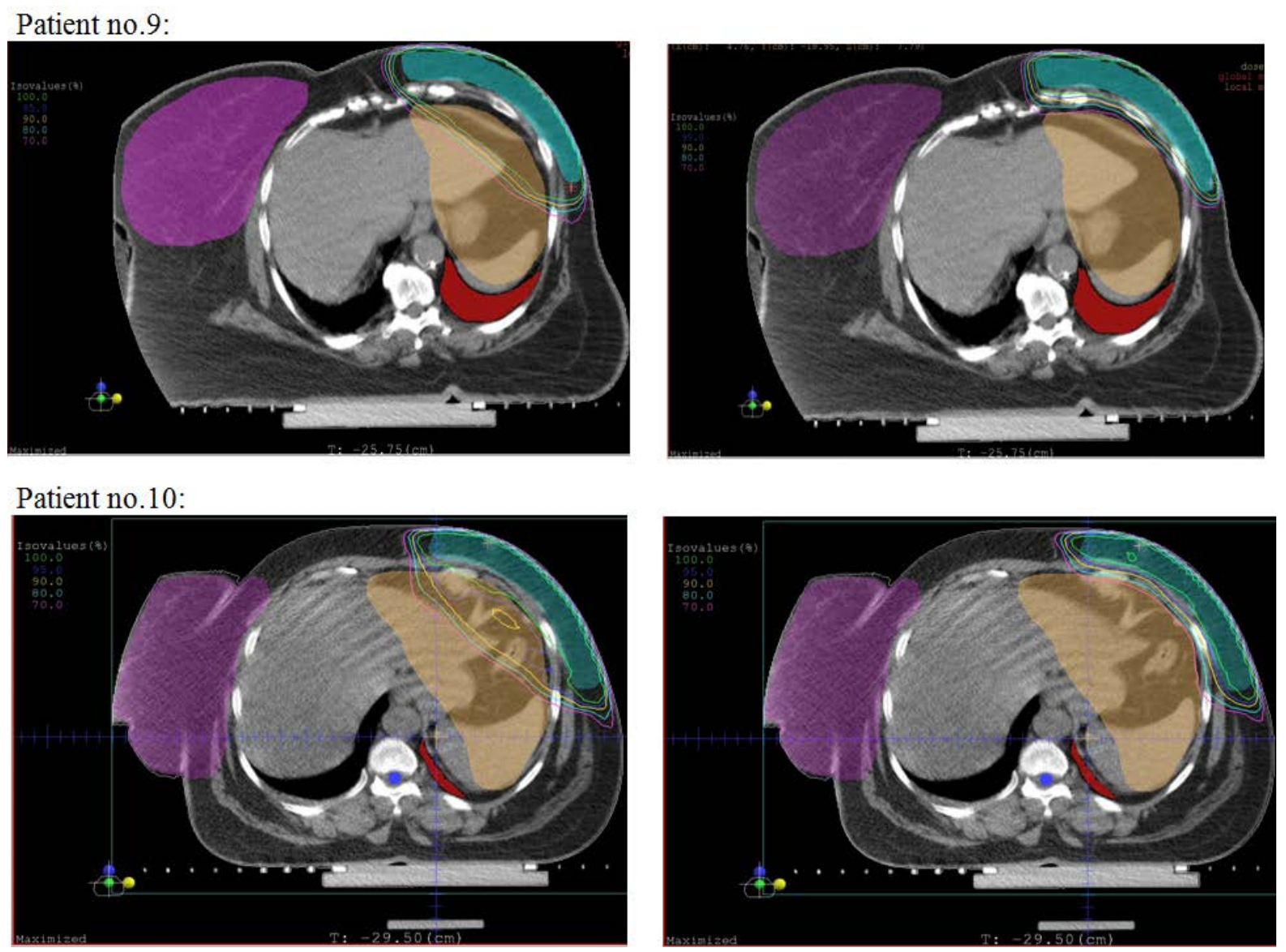

Figure 2. Group (a) and group (b): Showed two axial cuts for every one of ten left sided breast cancer patients showing the difference between isodose lines values that covered the OAR4 (the brown colored volume) as a Non-Taken Into-Account Volume (NTIAV) and as a Taken Into-Account Volume in IMRT treatment planning respectively.

stomach (as it is showed in Figure 2(a) patients no.7, 8, 9 and 10). These three portions in addition to other covered surrounded normal tissue volume were contained into the NTIAV delineation to be taken into consideration in plan dose calculation process to give those result showed in Figure 2(b) patients no.7, 8, 9 and 10.

\subsection{According to a Quantitative Evaluation tool (the DVHs)}

Figures 3(a)-(c): showed the Mean and Standard Deviation ( \pm SD) of minimum, maximum and mean doses received by PTV in Method 1 when OAR2 was taken into consideration in IMRT dose constraints and in Method 2 when it wasn't, are (43.06 $\pm 12.6,43.09 \pm 13)$, $(104 \pm 4.22,102.9 \pm 3.20)$ and $(92.3 \pm 0.69,91.9 \pm 0.84)$ respectively. It is noticed that the all values are approximately equal which means that there is no significant difference between the two methods with respect to PTV. But for OAR4, there is a very significant difference between the two methods which is shown in Figures 3(d)-(f) where the Mean and \pm SD of minimum, maximum and mean doses received by OAR4 in the two methods are ( $7.75 \pm 3.58,13 \pm 5.12),(72.46 \pm 12.22,94.52 \pm 2.86)$ and $(28 \pm 7.29,55 \pm 6.96)$ respectively.

Also, in all DVHs (Figure 4(a)), OAR4 (NTIAV) received lower dose in Method 1 than in Method 2 although of being the dose received by PTV not significantly affected in the two methods and Figure 4(b), showed that all OARs also not significantly affected in both two methods.

Also, we noticed that when the NTIAV is delineated but not taken into account in IMRT dose constraints it gave the same dose distribution as when that volume is not delineated (see Figure 5(a), Figure 5(b)). So, the delineation of that volume does not has any effect as long as it is not being taking into consideration in IMRT dose constraints or dose calculation process. 


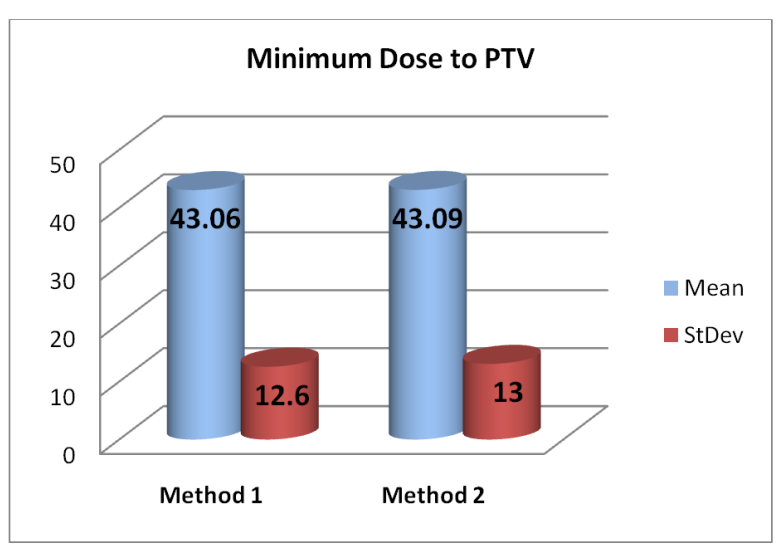

(a)

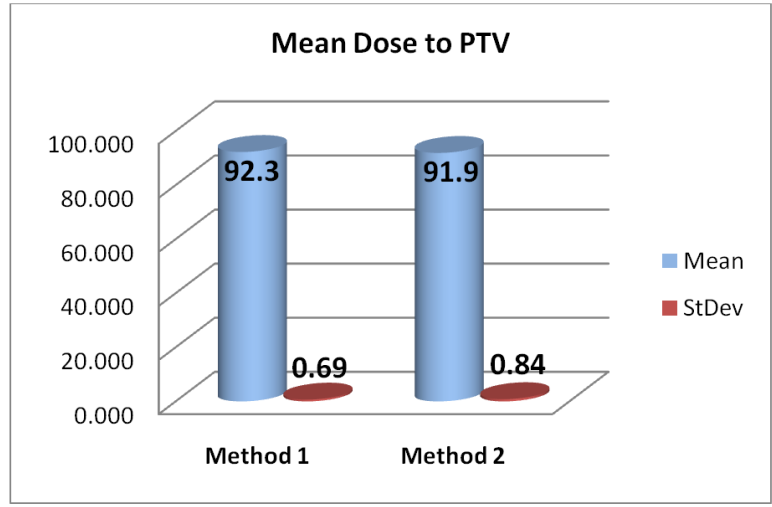

(c)

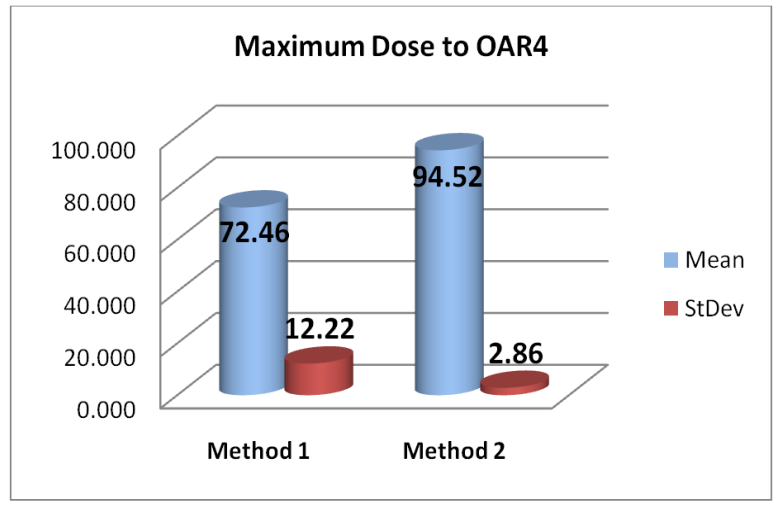

(e)

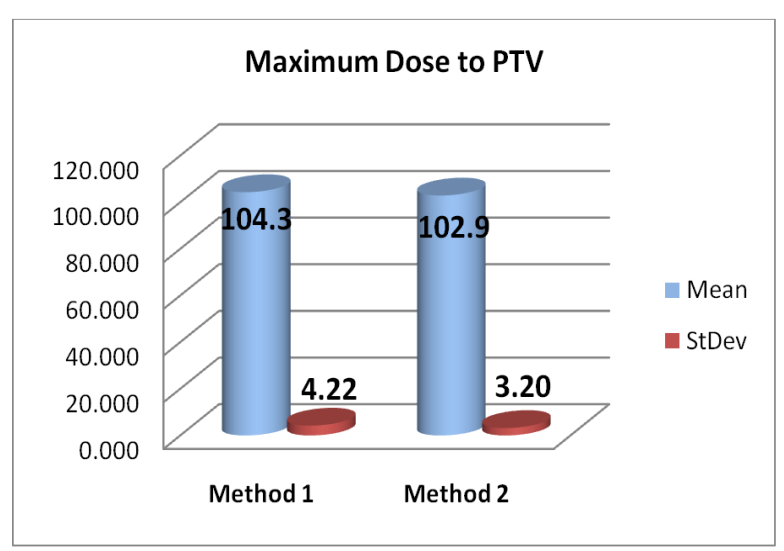

(b)

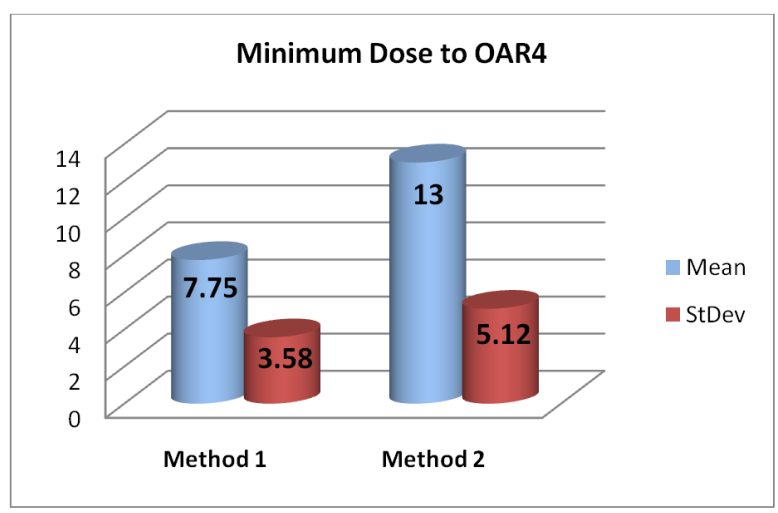

(d)

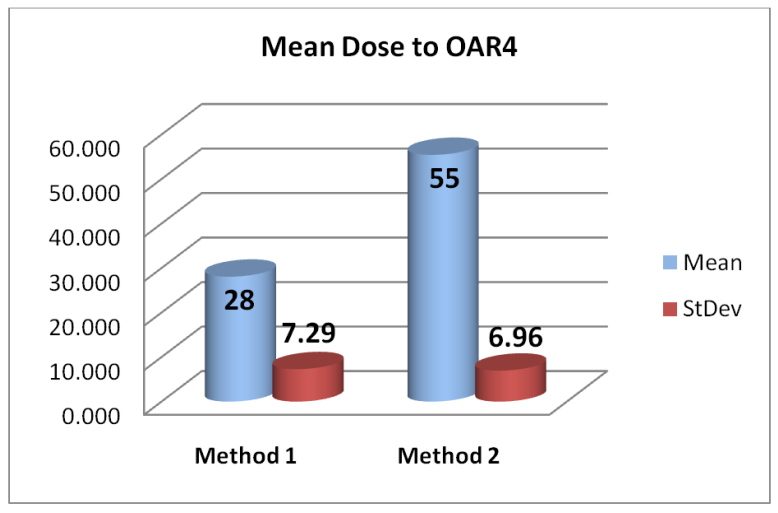

(f)

Figure 3. (a), (b) and (c): showed the mean and Standard Deviation of the minimum, maximum and mean doses received by PTV and (d), (e) and (f): showed the mean and SD of the minimum, maximum and mean doses received by OAR2 in the two methods 1 and 2. (Where Method 1: is when OAR2 was taken into consideration in IMRT dose constraints and Method 2: is when it wasn't.).

\section{Discussion}

Although of being many studies related to the use of IMRT for treating left breast cancer but we can't find any previous studies for this point of research.

\section{Conclusion}

According to all the previous results, we conclude and recommend that when the IMRT planning technique is 
Patient no. 1:
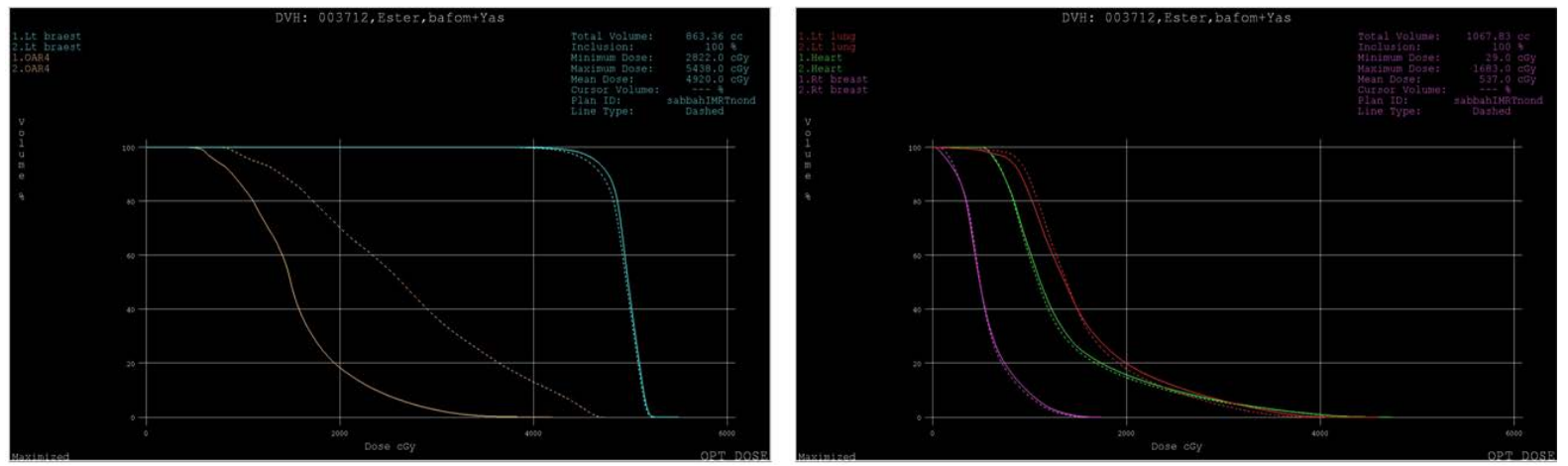

Patient no.2:
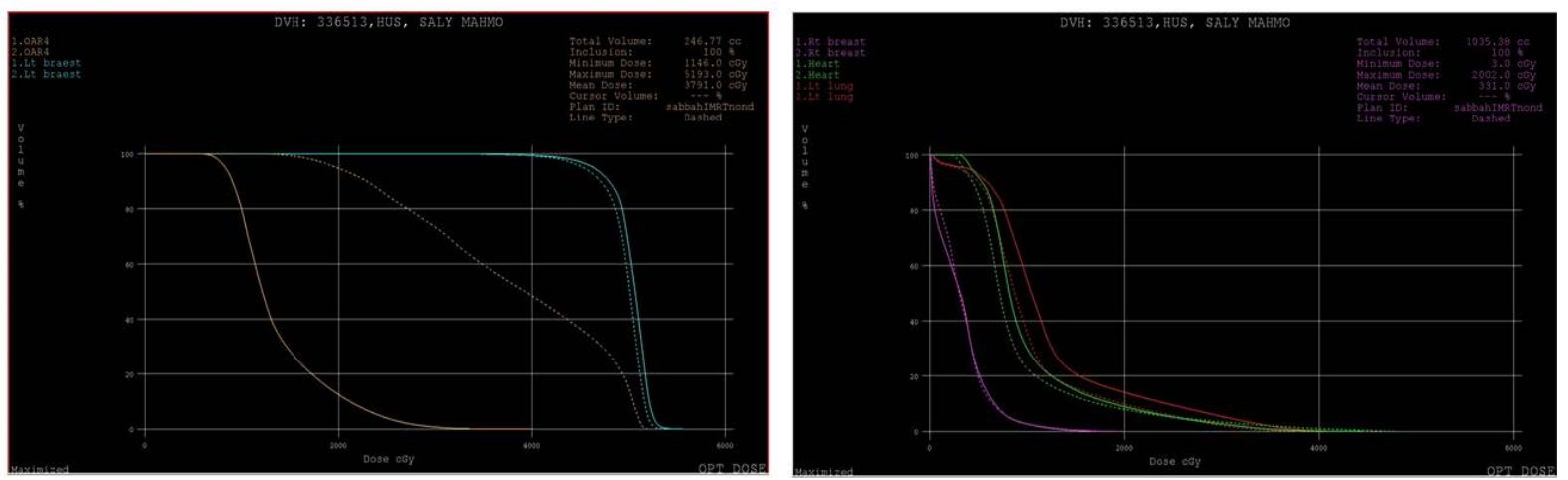

Patient no.3:
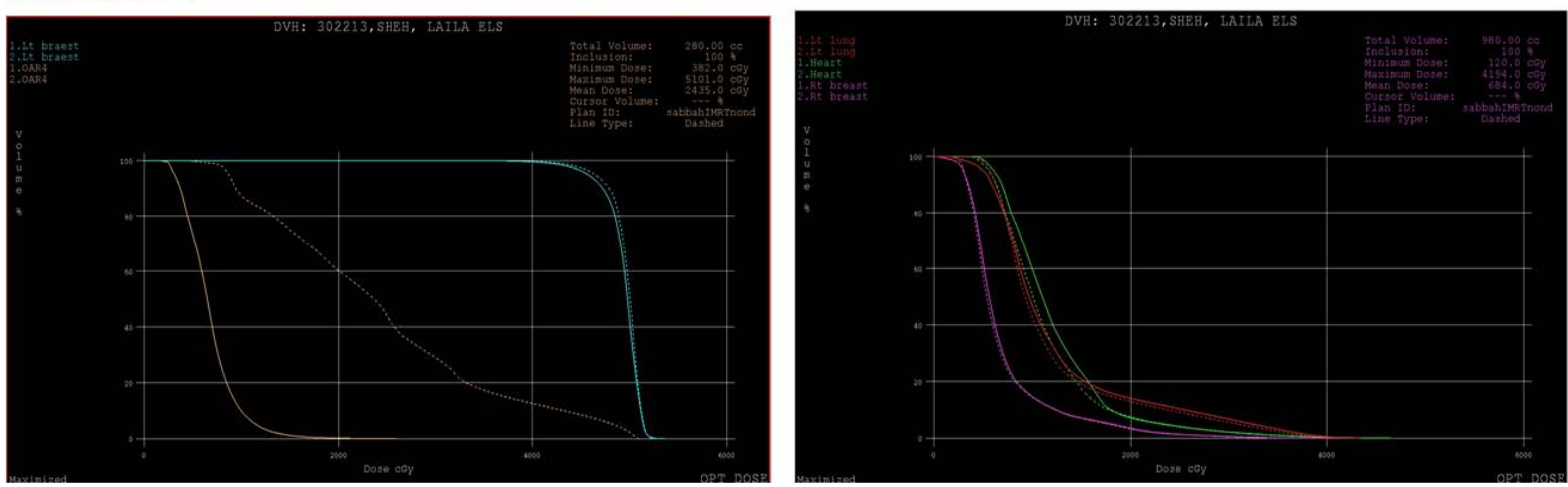

Patient no.4:
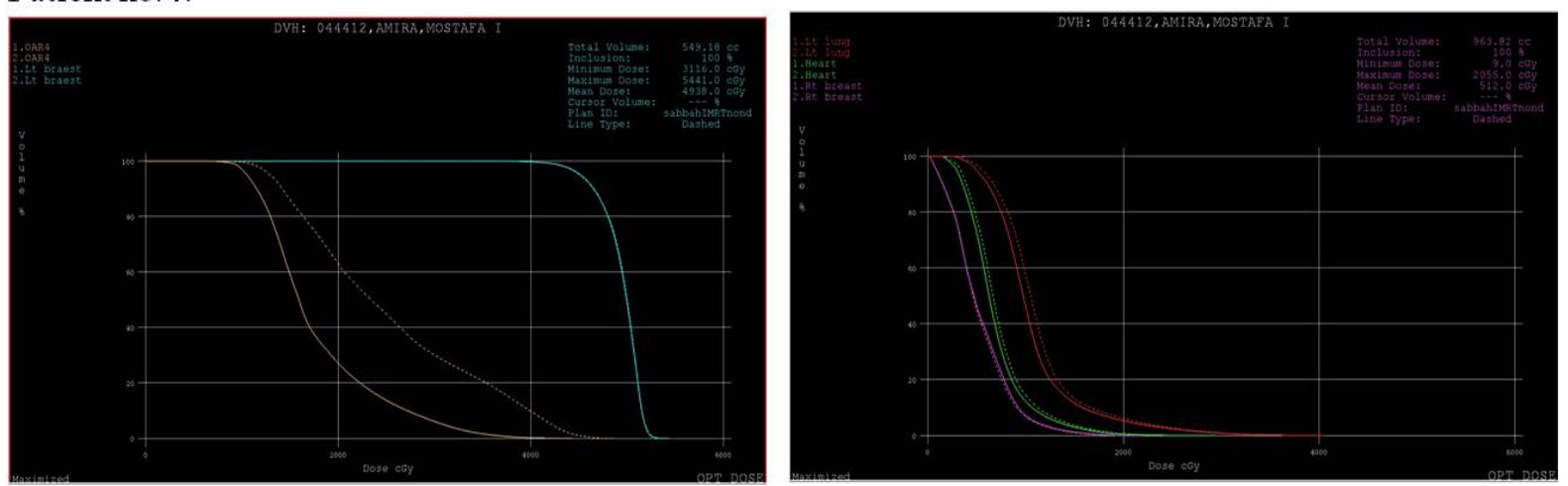

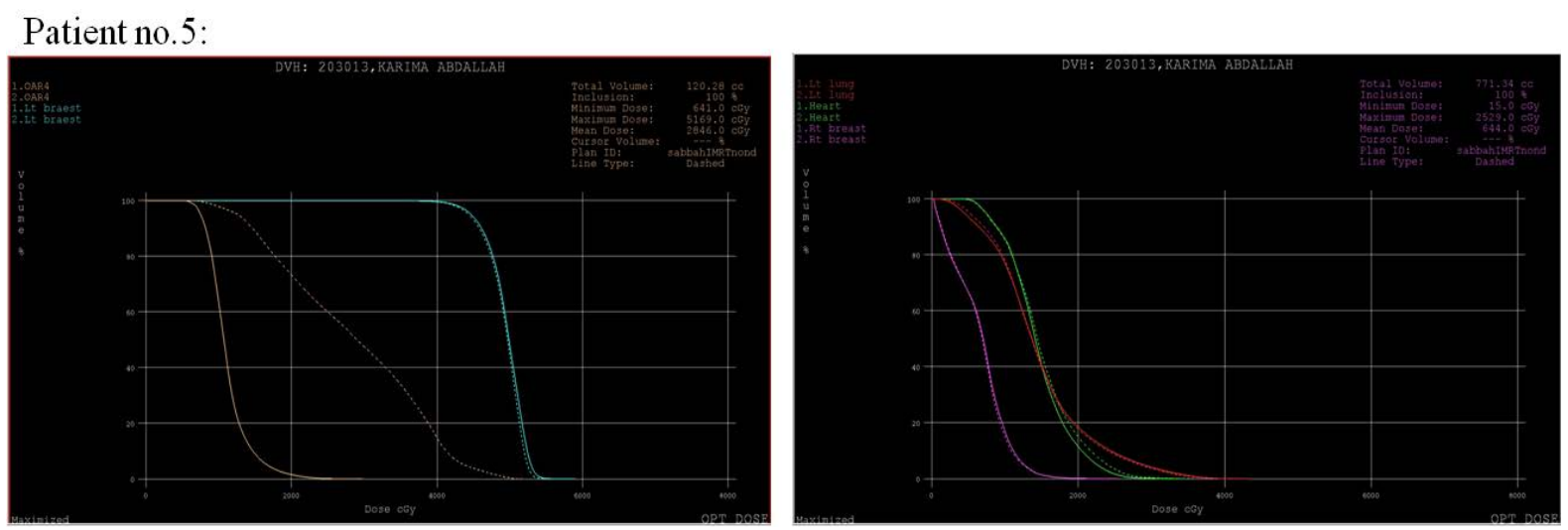

Patient no.6:
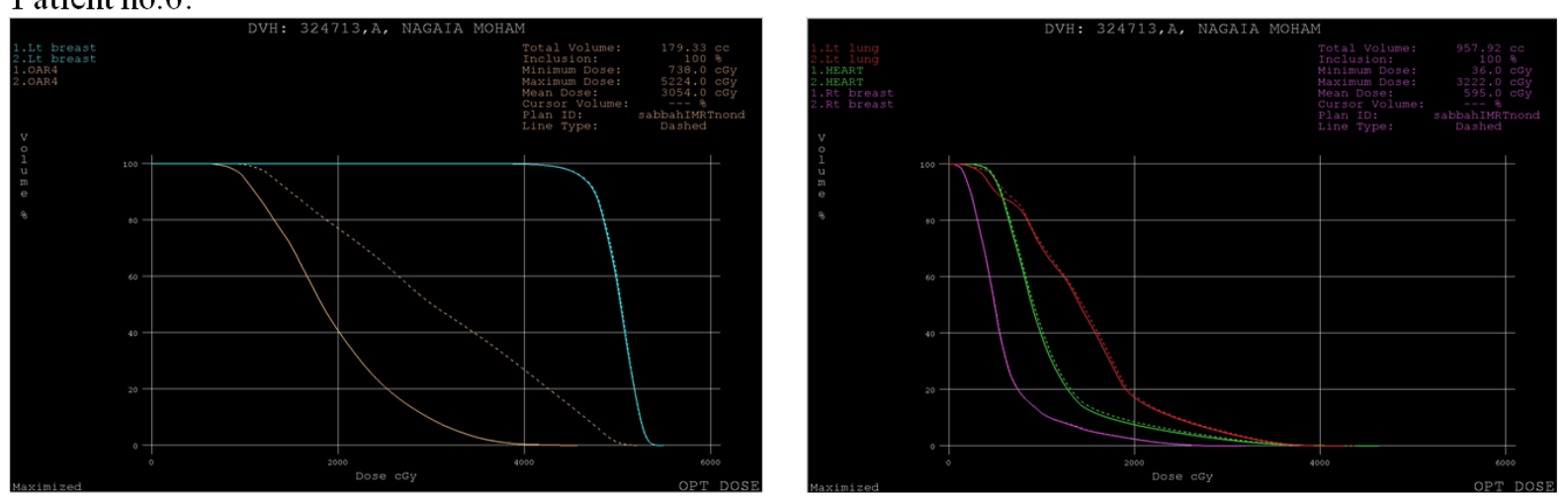

Patient no.7:
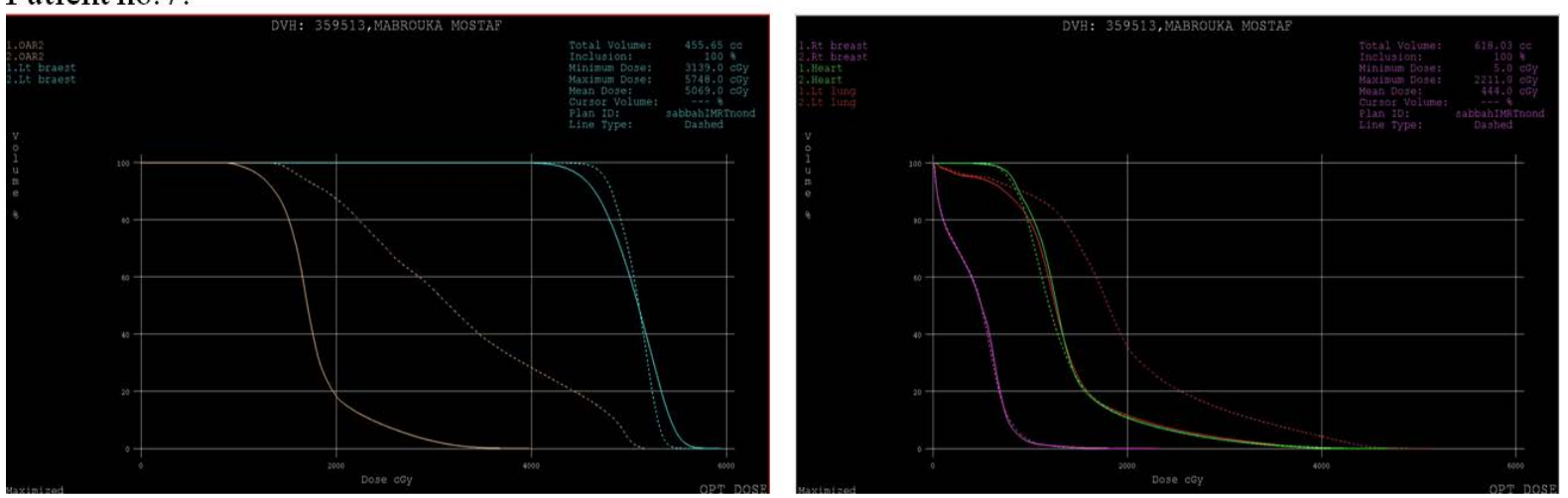

Patient no. 8:
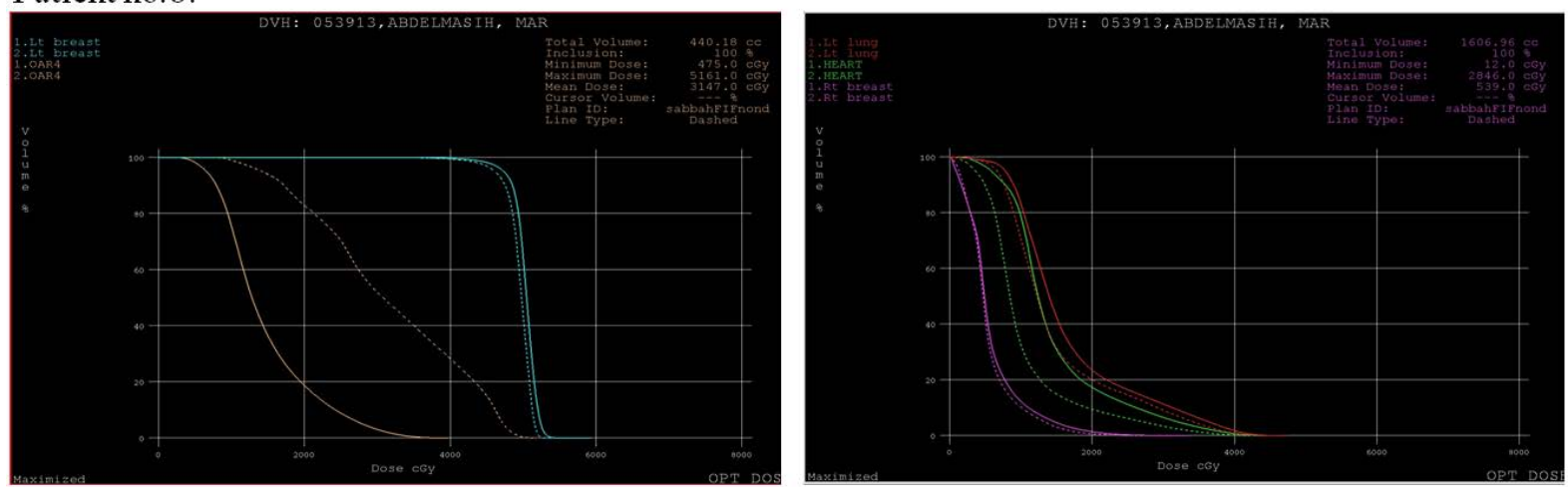

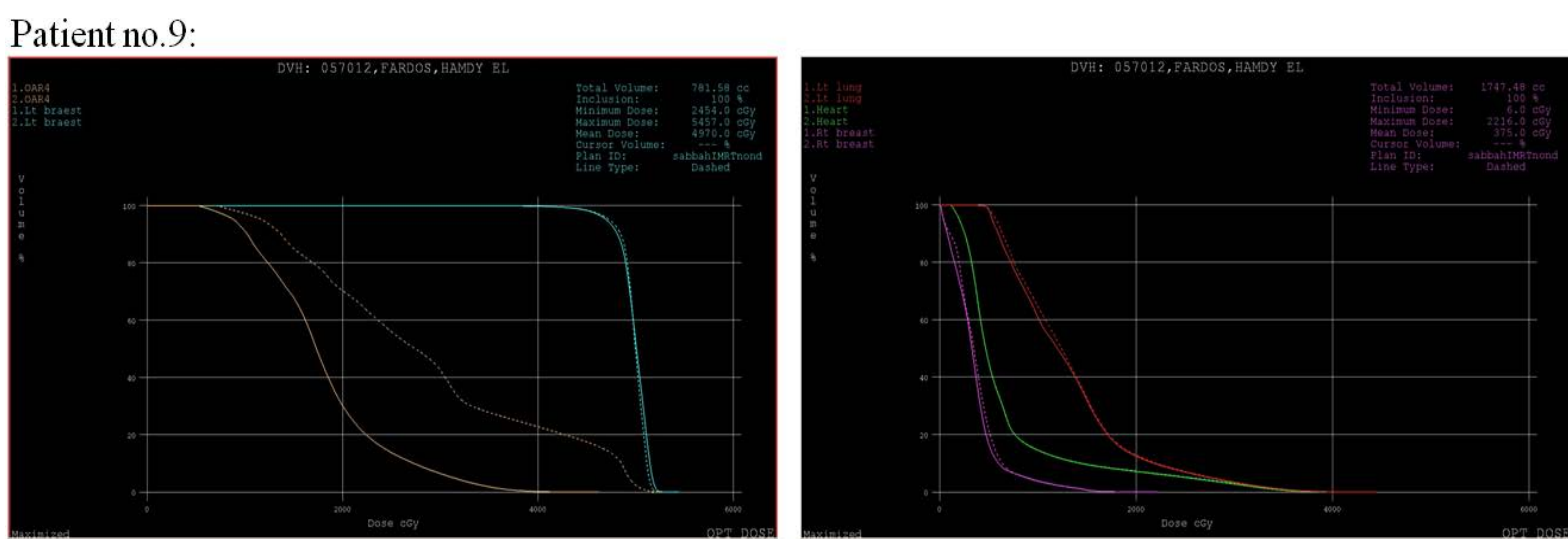

Patient no. 10:
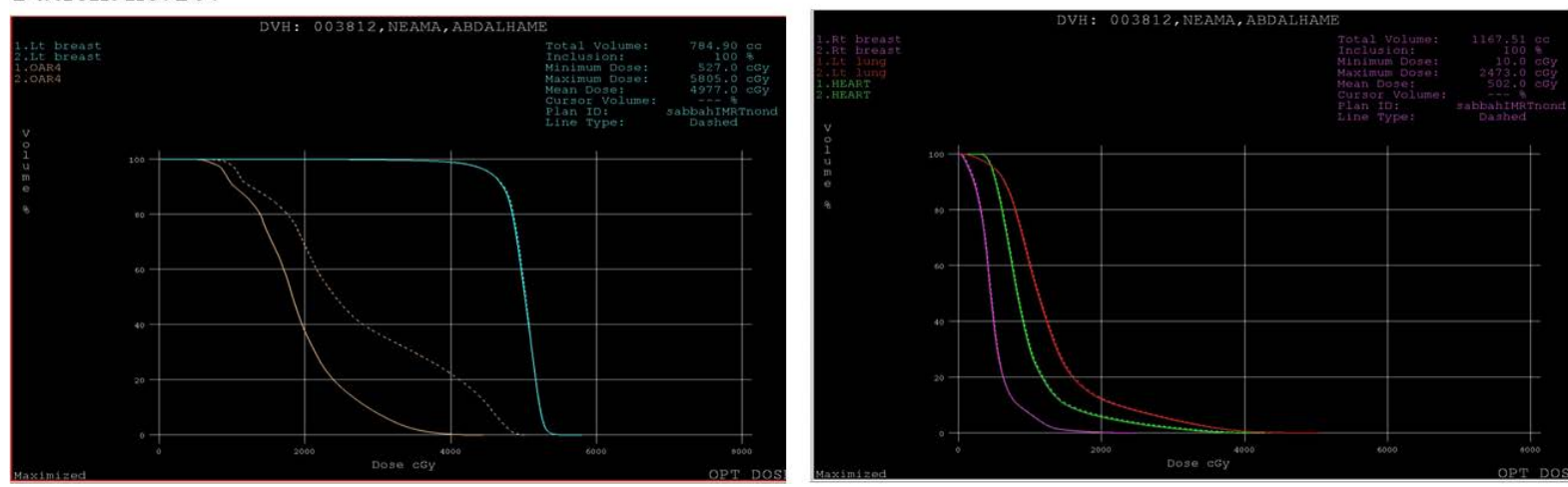

Figure 4. Group (a) and group (b): showed DVHs for PTV (cyan) and the OAR4 (brown) and OARs respectively for when the OAR4 is taken into account in the IMRT dose constraints (solid line), and when it didn't be taken into account in the IMRT dose constraints (NTIAV) (dashed line).

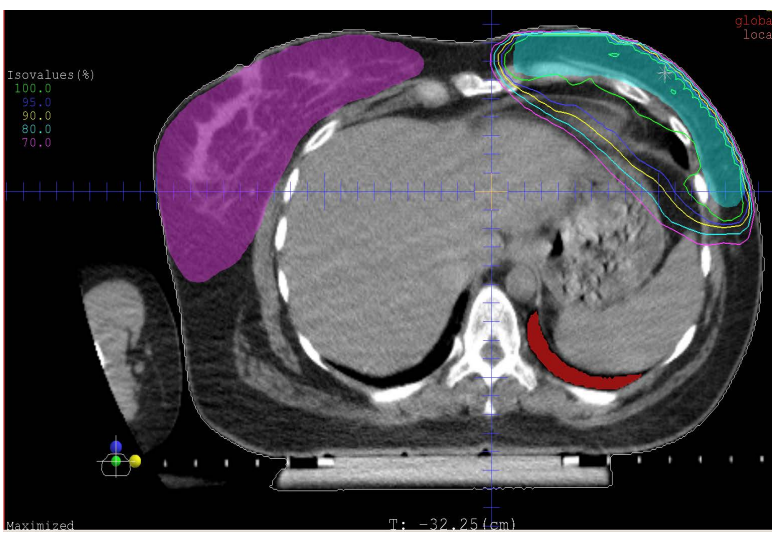

(a)

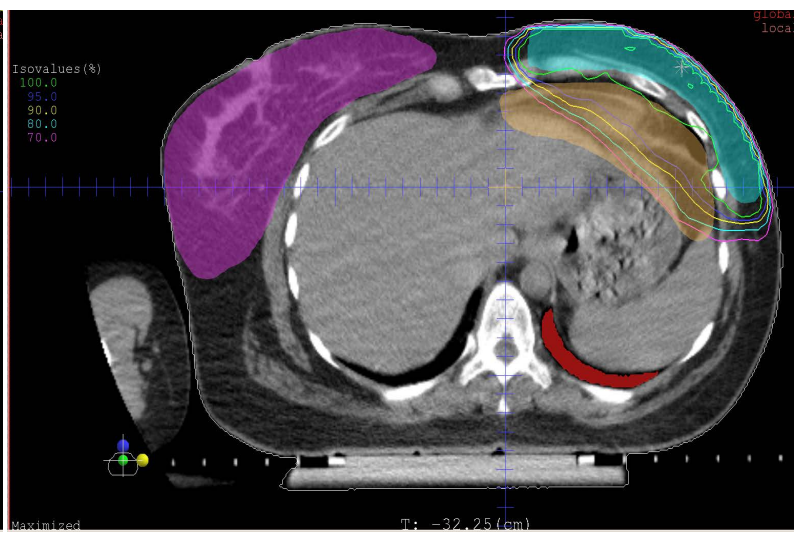

(b)

Figure 5. (a) and (b): Two print screens for the same axial cut of the same patient showing the same dose distribution of being the NTIAV not delineated and delineated but not taken into IMRT dose constraints account respectively.

used for treating left-sided breast cancer, all of the normal tissues/structures that are close to the treatment targets must be delineated and taken into account in the IMRT planning dose constraints even these volumes weren't usually considered as OARs like the stomach, liver, colon and any other healthy tissues coming into the radiation beam pathway.

As a future plan, we recommend that this point of research should be checked for all other tumor sites that can be treated using IMRT technique. 


\section{Acknowledgements}

The author thanks Prof. Dr. Assem Rostom, consultant clinical oncologist, the general manager of Alexandria Ayadi Almostakbl Oncology Centre (AAAOC) for his valuable support and encouragement.

\section{References}

[1] Vijayakumar, S. and Chen, G.T. (1995) Implementation of Three Dimensional Conformal Radiation Therapy: Prospects, Opportunities, and Challenges. International Journal of Radiation Oncology · Biology $\cdot$ Physics, 33, 979-983. http://dx.doi.org/10.1016/0360-3016(95)02060-8

[2] Prado, K.L., Starkschall, G. and Mohan, R. (2007) Three-Dimensional Conformal Radiation Therapy. In: Khan, F.M., Ed., Treatment Planning in Radiation Oncology, 2nd Edition, Lippincott Williams \& Wilkins, Philadelphia, 116-141.

[3] Tülay, E., Șefik, Ì., Gül, A., et al. (2010) Dosimetric Comparison of Field in Field Intensity-Modulated Radiotherapy Technique with Conformal Radiotherapy Techniques in Breast Cancer. Japanese Journal of Radiology, 28, 283-289. http://dx.doi.org/10.1007/s11604-010-0423-3

[4] (2014) Intensity-Modulated Radiation Therapy: Medical Policy. Proprietary Information of United Healthcare, Policy Number: 2014T0407M.

[5] Bucci, M.K., Alison, B. and Mack, R. (2005) Advances in Radiation Therapy: Conventional to 3D, to IMRT, to 4D, and Beyond. CA: A Cancer Journal for Clinicians, 55, 117-134. http://dx.doi.org/10.3322/canjclin.55.2.117

[6] Khan, F.M. (Ed.) (2010) Physics of Radiation Therapy. 4th Edition, Lippincott Williams \& Wilkins, Philadelphia, 431-432.

[7] Olivier, R., Pauline, R.M., David, A., Norbert, A., Jean-Bernard, D. and Pascal, F. (2013) Simultaneous Integrated Boost Plan Comparison of Volumetric-Modulated Arc Therapy and Sliding Window Intensity-Modulated Radiotherapy for Whole Pelvis Irradiation of Locally Advanced Prostate Cancer. Journal of Applied Clinical Medical Physics, 14, 26-32. http://www.jacmp.org/index.php/jacmp/article/download/4094/2967

[8] Mercè, B., Mónica, R., Juan, J.R., Santiago, P., Marc, S., Enrique, P., et al. (2012) Dose Variations in Tumor Volumes and Organs at Risk during IMRT for Head-and-Neck Cancer. Journal of Applied Clinical Medical Physics, 13, 1-7. http://dx.doi.org/10.1120/jacmp.v13i6.3723 or http://www.jacmp.org/index.php/jacmp/article/view/3723/2720

[9] ICRU (1999) International Commission on Radiological Units, Prescribing, Recording and Reporting Photon Beam Therapy. Supplement to ICRU 50, ICRU Report 62, Bethesda.

[10] Hande, B.A., Metin, G., Cemile, C., Nadir, K. and Kayihan, E. (2011) Comparison of Dose Distributions and Organs at Risk (OAR) Doses in Conventional Tangential Technique (CTT) and IMRT Plans with Different Numbers of Beam in Left-Sided Breast Cancer. Reports of Practical Oncology and Radiotherapy, 16, 95-102. http://dx.doi.org/10.1016/j.rpor.2011.02.001

[11] Webb, S., Convery, D.J. and Evans, P.M. (1998) Inverse Planning with Constraints to Generate Smoothed Intensity Modulated Beams. Physics in Medicine and Biology, 43, 2785-2794. http://dx.doi.org/10.1088/0031-9155/43/10/008

[12] Guckenberger, M., Pohl, F., Baier, K., Meyer, J., Vordermark, D. and Flentje, M. (2006) Adverse Effect of a Distended Rectum in Intensity-Modulated Radiotherapy (IMRT) Treatment Planning of Prostate Cancer. Radiotherapy and Oncology, 79, 59-64. http://dx.doi.org/10.1016/j.radonc.2006.03.004

[13] Sarah, R., Wim, D., Karin, H., et al. (2006) Definition and Delineation of the Clinical Target Volume for Rectal Cancer. International Journal of Radiation Oncology · Biology $\cdot$ Physics, 65, 1129-1142. http://dx.doi.org/10.1016/j.ijrobp.2006.02.050

[14] Chui, C.S., Chan, M.F., Yorke, E., Spirou, S. and Ling, C.C. (2001) Delivery of Intensity-Modulated Radiation Therapy with a Conventional Multileaf Collimator: Comparison of Dynamic and Segmental Methods. Medical Physics, 28, 2441-2449. http://dx.doi.org/10.1118/1.1418018

[15] Jin, G.-H., Chen, L.-X., Deng, X.-W., Liu, X.-W., Huang, Y. and Huang, X.-B. (2013) A Comparative Dosimetric Study for Treating Left-Sided Breast Cancer for Small Breast Size Using Five Different Radiotherapy Techniques: Conventional Tangential Field, Filed-in-Filed, Tangential-IMRT, Multi-Beam IMRT and VMAT. Radiation Oncology, 8, 89. http://dx.doi.org/10.1186/1748-717X-8-89

[16] Fallon Community Health Plan (2009) Conformal and Intensity Modulated Radiation Therapy (IMRT) of the Breast. Policy number: 200909-0002, 1-9.

[17] Alison, L.S., Tomas, K., Alan, H., et al. (2011) Does Inverse-Planned Intensity-Modulated Radiation Therapy Have a Role in the Treatment of Patients with Left-Sided Breast Cancer? Journal of Medical Imaging and Radiation Oncology, 55, 311-319. http://dx.doi.org/10.1111/j.1754-9485.2011.02273.x

[18] Giorgio, P., Lucag, R., Christian, F., et al. (2011) Geometric and Dosimetric Approach to Determine Probability of Late Cardiac Mortality in Left Tangential Breast Irradiation: Comparison between Wedged Beams and Field-in-Field 
Technique. International Journal of Radiation Oncology $\cdot$ Biology $\cdot$ Physics, 81, 894-900. http://dx.doi.org/10.1016/j.ijrobp.2010.12.021

[19] Rowse, R. (2012) 3D Tangential Wedge Pair Radiotherapy Planning versus 3D Forward Planned IMR T for Breasts in the Reduction of Hot Spots and Cardiac Doses. (A Feasibility Study). Radiography, 18, 68-73.

http://dx.doi.org/10.1016/j.radi.2011.12.002

\section{Abbreviations and Acronyms}

IMRT: Intensity-Modulated Radiation Therapy

DVH: Dose Volume Histogram

NTIAV: Non-Taken Into-Account Volume

CRT: Conformal Radiation Therapy

CT: Computed Tomography

GTV: Gross Target Volume

CTV: Clinical Target Volume

PTV: Planning Target Volume

OAR: Organ at Risk

TPS: Treatment Planning System

CMS: Computerized Medical Systems

$\mathrm{XiO}$ : name of three dimensions treatment planning system

MUs: Monitor Units

VOI: Volume of Interest 
Scientific Research Publishing (SCIRP) is one of the largest Open Access journal publishers. It is currently publishing more than 200 open access, online, peer-reviewed journals covering a wide range of academic disciplines. SCIRP serves the worldwide academic communities and contributes to the progress and application of science with its publication.

Other selected journals from SCIRP are listed as below. Submit your manuscript to us via either submit@scirp.org or Online Submission Portal.
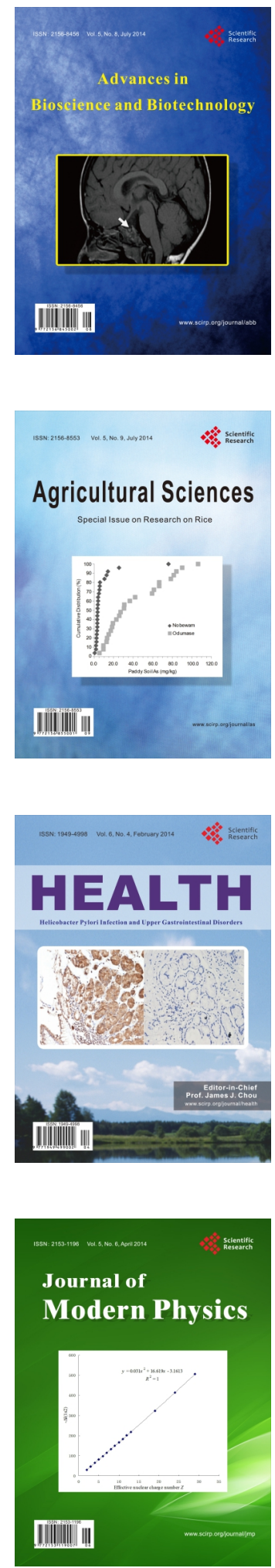
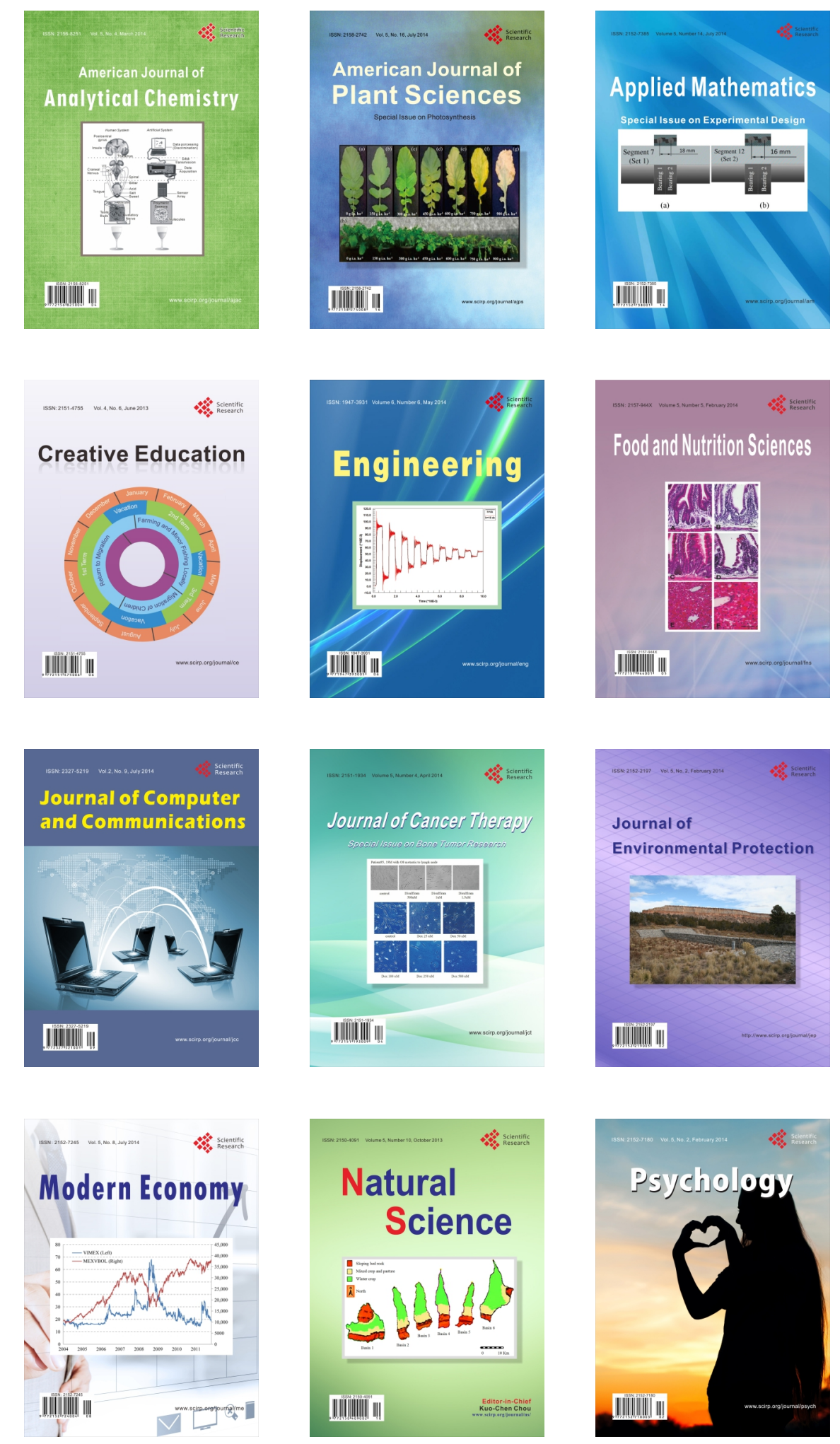